\title{
Consistent Frequency of Color Morphs in the Sea Star Pisaster ochraceus (Echinodermata:Asteriidae) across Open-Coast Habitats in the Northeastern Pacific ${ }^{1}$
}

\author{
Peter T. Raimondi, ${ }^{2}$ Raphael D. Sagarin, ${ }^{3,4}$ Richard F. Ambrose, ${ }^{5}$ Christy Bell, ${ }^{2}$ Maya George, ${ }^{2}$ \\ Steven F. Lee, ${ }^{5}$ David Lobse, ${ }^{2}$ C. Melissa Miner, ${ }^{2}$ and Steven N. Murray ${ }^{6}$
}

\begin{abstract}
The sea star Pisaster ocbraceus (Brandt, 1835) is among the most conspicuous members of northeastern Pacific rocky-shore fauna due to its dramatic color variation, ranging from bright yellowish orange to brown to deep purple. Despite a large body of ecological and developmental biology information on $P$. ochraceus, few studies have rigorously examined color patterns or their causes across its geographic range. We used thousands of observations of sea star color and size taken from southern California to northern Oregon to show that the frequency of orange sea stars is approximately $20 \%$ with little variation across a broad latitudinal band. However, the frequency of orange sea stars in a population increases with the size of the animals in most populations. We consider several alternative hypotheses for these color patterns but find that the most parsimonious explanation is that adult color is a selectively neutral genetic trait that expresses itself ontogenetically. These novel findings point to the need for renewed study of the basic biology of this key ecological species.
\end{abstract}

ONE OF THE MOST immediately conspicuous observations in northeastern Pacific tide pools is the striking color differences in the sea star Pisaster ocbraceus (Brandt, 1835). Even at a distance one can easily pick out orange and purple sea stars as they line the rock walls near intertidal mussel beds. Anecdotally, ex-

${ }^{1}$ This is contribution number 226 of the Partnership for Interdisciplinary Studies of Coastal Oceans (PISCO) funded primarily by the Gordon and Betty Moore Foundation and the David and Lucile Packard Foundation. Manuscript accepted 9 June 2006.

${ }^{2}$ Long Marine Laboratory, University of California, 100 Shaffer Road, Santa Cruz, California 95060.

${ }^{3}$ Corresponding author (e-mail: rafe.sagarin@duke .edu).

${ }^{4}$ Nicholas Institute for Environmental Policy Solutions, Duke University, Durham, North Carolina 27708.

${ }^{5}$ University of California, Department of Environmental Health Sciences, Los Angeles, California 900951772.

${ }^{6}$ Department of Biological Science and College of Natural Sciences and Mathematics, California State University, Fullerton, Fullerton, California 92834-6850.

Pacific Science (2007), vol. 61, no. 2:201-210

(C) 2007 by University of Hawai'i Press

All rights reserved perienced intertidal biologists have observed that about one-fourth to one-third of the $P$. ochraceus in any given site along the open Pacific coast are orange, and the remainder are some variant of brown, rust, or purple (E. Sanford, J. Pearse, R. Strathmann, and C. Harley, pers. comm. to R.D.S. 2004). Although P. ochraceus is one of the most extensively studied intertidal invertebrates, with many published studies, for example, on its development (George 1999), physiology (Vasu and Giese 1966), diet (Feder 1959, Menge 1972), effects on prey species (Mauzey et al. 1968), parasitism (Leighton et al. 1991), settlement patterns (Sewell and Watson 1993), role as a "keystone" species (Paine 1966, Menge et al. 2004) and in maintaining alternate community states (Paine and Trimble 2004), and reactions to climatic change (Sanford 1999), remarkably little is known about the basic biological foundations of its color variants nor the ecological conditions that support phenotypic color polymorphism in this sea star. Most of what we know about color morphs in $P$. ochraceus stems from studies done more than half a century ago on small numbers of individuals from just one or two locations. 
Fox and Scheer (1941) confirmed that color in $P$. ochraceus is determined by two carotenoid pigments, suggesting that diet plays a role in coloration because animals generally do not produce carotenoids. Beyond that paper, an unpublished study of variation in color polymorphism by Forbes (1951), and a review by Fox and Hopkins (1966), none of the 128 published works on $P$. ocbraceus indexed by ISI Web of Knowledge between 1910 and 2005 nor the citations on P. ochraceus reviewed in Intertidal Invertebrates of California (Morris et al. 1980) addressed color patterns in $P$. ochraceus or the mechanisms for them.

Phenotypic color polymorphism in other organisms has been commonly observed (Endler 1986, Galeotti et al. 2003, Wente and Phillips 2003) and has generated numerous evolutionary explanations for why sometimes strikingly different colors should be maintained. In almost all studies, the null hypothesis that color polymorphism is selectively neutral has been rejected. Although color polymorphism without an obvious selective mechanism is unexpected, it is not unprecedented. Oda and Ishii (2001) demonstrated that color polymorphism in Conocephalus maculatus katydids is genetically determined but not under environmental selection, and Finke (1994) found no sexual, apostatic, or disruptive selective mechanisms acting on female color dimorphism in Enallagma damselflies.

Alternative hypotheses generally can be classified as invoking either selective mechanisms that have a persistent effect on populations or transient mechanisms that rely on a phenotypically plastic trait. Alternative hypotheses with empirical support based on selective mechanisms include (1) nonrandom mating due to sexual selection or signaling to prevent inbreeding (Houde 1987, Galeotti et al. 2003); (2) apostatic selection, in which rare morphs are more successful in hunting prey or avoiding predators through the disruption of search images or advertisement of distastefulness (Allen 1988, Gillespie and Oxford 1998, Horth 2004); (3) disruptive selection through crypsis in heterogeneous backgrounds or physiological adaptation to spatially or temporally variable environments
(Nevo 1973, Hairston 1979, Etter 1988); and (4) balancing trade-offs among these agents. Mechanisms invoking plasticity include the roles of (1) color plasticity in response to environmental factors (Wente and Phillips 2003); (2) dietary differences resulting in phenotypic differences (Tlusty and Hyland 2005); and (3) ontogenetic color change (Booth 1990).

With so many potential mechanisms, it may not be logistically feasible to study color polymorphism in a species across a large range using detailed mechanistic experiments such as those used on smaller scales or on easily manipulated study systems (e.g., laboratory experiments with guppies). However, a common theme to almost all alternative hypotheses is that color morphs are segregated into different spatial, temporal, ontogenetic or behavioral niches for which the different color morphs are better adapted. This suggests that broad-scale observations of color morphs taken across an environmental gradient containing many of these niches, combined with an understanding of the natural history of an organism, can begin to eliminate the likelihood of certain hypotheses while suggesting more-likely hypotheses that could be addressed with specific mechanistic studies. Here we use an unprecedented number of color and size observations obtained over a wide latitudinal gradient to examine alternative hypotheses related to the maintenance of color polymorphism in $P$. ochraceus.

\section{MATERIALS AND METHODS}

Samples of Pisaster ochraceus size and color were taken by three different groups of investigators that share data as part of the MultiAgency Rocky Intertidal Network (MARINe) and the Partnership for Interdisciplinary Studies of Coastal Oceans (PISCO). Samples were taken biannually between fall 2000 and fall 2003 at 26 sites located between southern California $\left(33.71^{\circ} \mathrm{N}\right)$ and northern Oregon $\left(45.92^{\circ} \mathrm{N}\right)$ within permanent demarcated plots in the low intertidal (Figure 1). Sizes of the plots varied with site, ranging from 20 to $160 \mathrm{~m}^{2}$, depending on geomorphology and available habitat. Because our goal was 


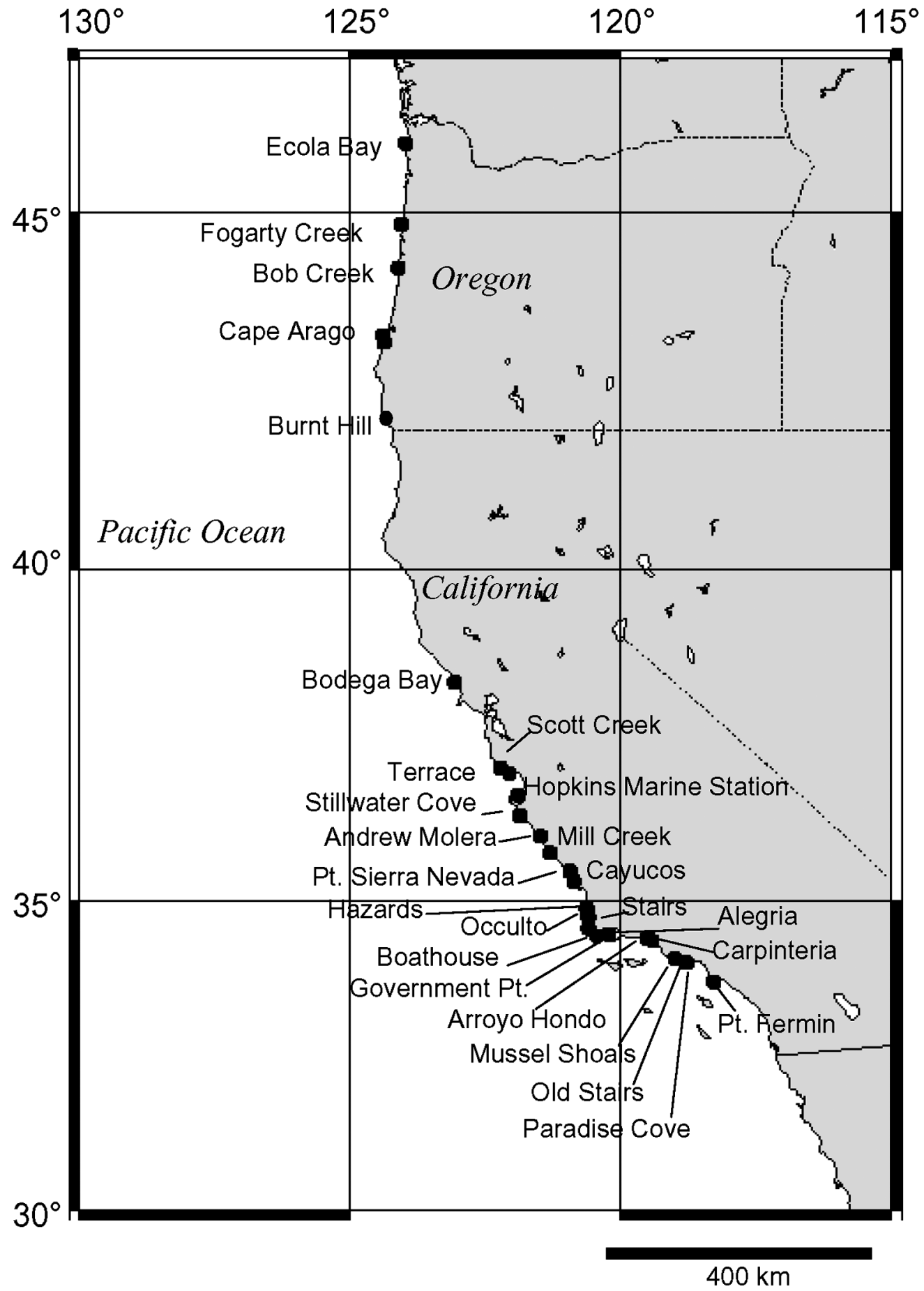

FIgURE 1. Map of 26 study sites along the west coast of North America. 
specifically to measure and record the color of many individuals at each site, plots were chosen to represent a range of habitat types (e.g., low intertidal crevices, rock walls, and pools) where $P$. ochraceus of all postsettlement life stages can be found, rather than a stratified random plot design (which would be more appropriate if the goal was to compare population size estimates).

Sites were sampled by MARINe researchers from University of California, Los Angeles (UCLA), and the University of California, Santa Cruz (UCSC), and PISCO researchers from UCSC. Because our sampling methodology is relatively simple and was conducted by experienced intertidal researchers who frequently communicate about sampling issues, differences due to observer bias in recording color or size across sites is unlikely.

Our study sites are wave-exposed open coast areas that represent the most common $P$. ocbraceus habitat over most of its geographic range. We also used additional observations by ourselves and others from protected-water sites in Puget Sound (Washington State) and Vancouver Island, British Columbia, to gain insight into the open-coast patterns we report. Along the 1,850-km stretch of open coast from Baja California to Oregon, and farther north, sea stars generally occur in orange, purple, and brown color morphs. All sampled sea stars were measured and scored for color as either "orange" or "purple" (all brown and darker shades were scored in the "purple" category because field tests determined that brown and purple forms are difficult to differentiate consistently). Although there is considerable color variation among the darker forms in this species, we use this simple orange/purple dichotomy in our observations and analysis because it is least likely to introduce sampling bias while still offering the ability to evaluate the orange color morph patterns observed in the field.

Size measurements were made with calipers or rulers from the tip of the longest arm to the center of the aboral disk and recorded to the nearest $10 \mathrm{~mm}$. Pilot data from 438 individuals confirmed a strong correlation between this radial measurement and oral disk radius (Pearson correlation coefficient $=$
$0.879, P<.001)$ and width of the largest arm (Pearson correlation coefficient $=0.904$, $P<.001$ ), indicating that maximum radius is representative of size.

Our analysis was designed to focus on color ratios and to avoid issues of nonindependence that might arise from repeatedly sampling individuals in permanent quadrats. Hence, at each site we calculated the percentage of orange individuals for each sample period and then averaged those percentages to produce an overall site average. To examine the percentage of orange individuals in populations of different sizes the mean number of purple and orange individuals for each 10$\mathrm{mm}$ size bin across all sample periods was calculated for each site. Means were then summed for these color categories across all sites and the percentage of orange morphs was calculated. By aggregating our data, the potential problem of near-zero or zero values in the smallest and largest size categories was avoided.

Finally, habitat use, aggregation by color, and seasonal differences in color ratios were tested using quantitative analyses (chi square and analysis of variance [ANOVA]), specialized data collection efforts, and through qualitative observations made during sampling visits.

\section{RESULTS AND DISCUSSION}

The monitoring data analyzed here, incorporating 14,720 observations of Pisaster ochraceus, demonstrate both consistency of orange color frequencies in adult sea stars over a broad latitudinal gradient (Figure 2) and changes in the frequency of orange morphs from small to large sea stars at most sites (Figure 3). The range in percentage orange morphs for all sites was $12.6-27 \%$ (mean = $20.0 \pm 4.4 \%$ SD). Regression of percentage orange against size was positive and highly significant $\left(R^{2}=0.74, P<.001\right)$.

Observations of 177 individuals from Hopkins Marine Station (central California) and Old Stairs (southern California) showed no relationship between color and habitat type (flat benches, vertical walls, or shaded crevices) (Pearson chi-square $=1.38, \mathrm{df}=2$, 

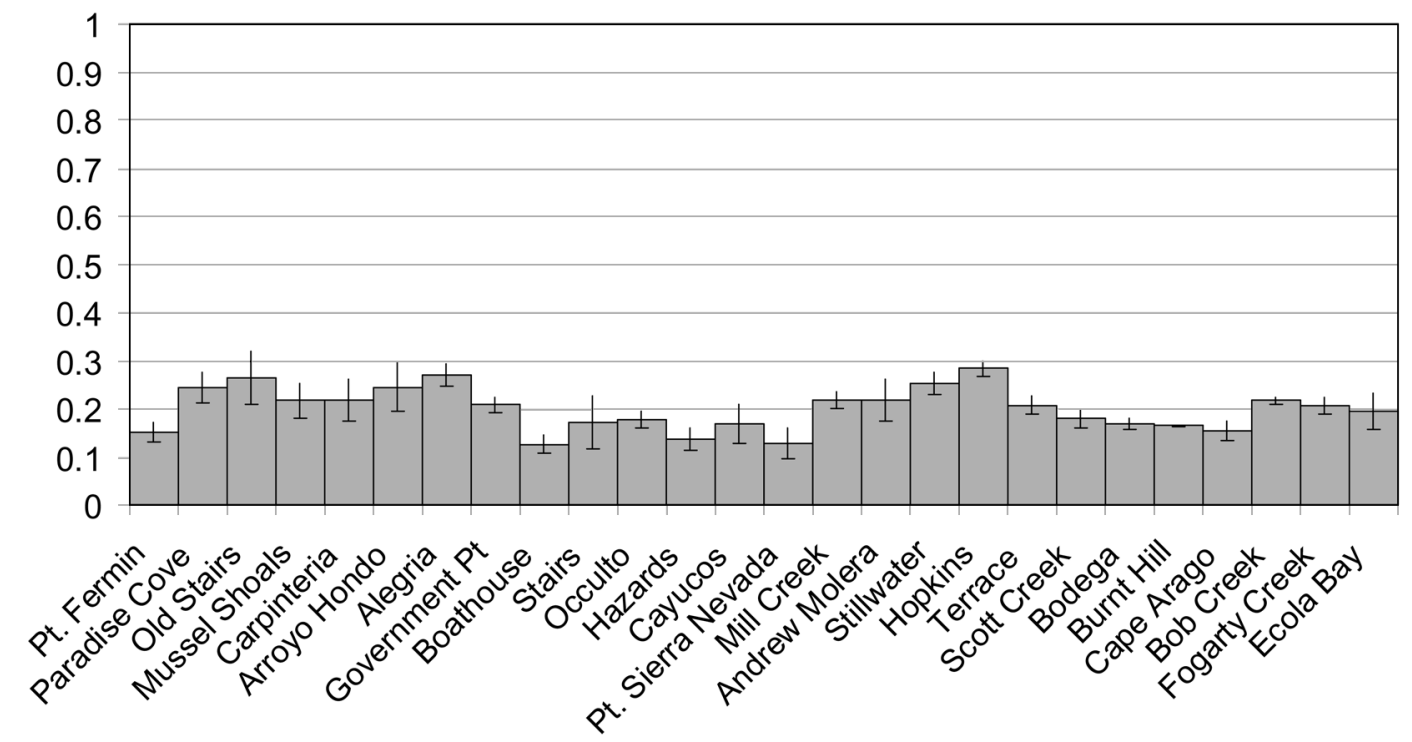

FIGURE 2. Average percentage of orange sea stars $( \pm S E)$ in the population at all sites, arranged from south to north.

$P=.501)$. Similarly, clustering of color morphs was not detected because $24 \%$ of nonorange sea stars were found closest to orange individuals and $78 \%$ of orange sea stars, mirroring the overall color frequencies, were found closest to nonorange sea stars. These

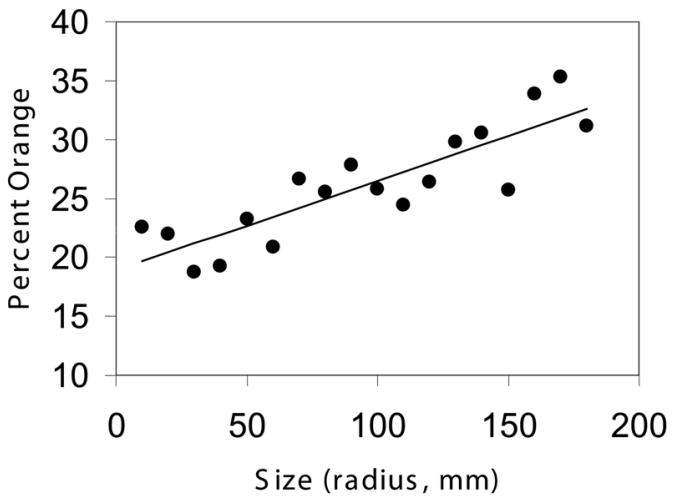

Figure 3. Percentage of orange sea stars in increasing size bins. The mean number of purple and orange individuals for each $10-\mathrm{mm}$ size bin across all sample periods was calculated at each site. Means were summed for each color across all sites and percentage orange was calculated. results are in accordance with qualitative observations of the frequency of color morphs in this species that we made during hundreds of sampling visits. Finally, we found no evidence of consistent seasonal differences in the percentage of $P$. ochraceus orange color morphs in our sampled populations (ANOVA, $F=1.09$, $\mathrm{df}=45, P=.364)$.

\section{Selective Mechanisms}

The wealth of knowledge on $P$. ochraceus raises doubts about hypotheses that invoke selective mechanisms as viable explanations for color polymorphism in this species. These sea stars are dioecious, broadcast spawners with little visual ability beyond sensing light and dark (Morris et al. 1980). Hence, it is unlikely that color serves as a cue for sexual or other forms of visually based selection. The sea star's main prey items are sessile and use only size as an escape from predation, or use their mobility to escape by responding to chemical traces of the predator in the water (Phillips 1975, Morris et al. 1980). Thus, color differences would not afford any color morph an advantage in obtaining prey. 
Among larger ( $>30$-mm radius) individuals, no $P$. ochraceus color morph is cryptic in intertidal habitats. Greater mortality in purple $P$. ochraceus could lead to an increase in the frequency of orange sea stars in a population. However, predation on sea stars is not commonly observed, although sea otters prey on $P$. ochraceus, and seagulls are occasionally observed pulling sea stars off intertidal rocks. If relying on visual cues (whether color or monochromatic), these visual predators would likely target the more conspicuous orange sea stars, which contrast more strongly with the coloration patterns of intertidal habitats. Although it is plausible that experience with sea stars or some color-specific olfactory signal could impart a preference for purple stars if orange stars are less palatable, to date no one has investigated this hypothesis. However, as Ricketts and Calvin (1939:116-117) explained, "Pisaster neither has nor seems to need protective coloration. Anything that can damage this thoroughly tough animal, short of the 'acts of God' referred to in insurance policies, deserves respectful mention."

Across the geographic range of our study sites, intertidal communities experience widely different climatic conditions, tidal regimes, and species assemblages, and yet the ratio of orange morphs to other color variants remains similar. Moreover, the different color morphs of $P$. ochraceus do not segregate into different niches-spatially, temporally, or behaviorally. Our observations collected over 120 sampling visits, as well as those of numerous intertidal ecologists, suggest that color morphs do not separate into different intertidal habitats, nor do they aggregate preferentially, or show a seasonal component to color dominance. These observations were supported by our more-detailed scoring of habitat use and aggregation by color at Hopkins Marine Station and Old Stairs sites, as well as the quantitative analysis of our data parsed by season. Finally, populations appear to be well mixed genetically across their range. Recent work by Harley et al. (in press) revealed no geographic genetic population structure across the species range, even when comparing locations on alternate sides of known biogeographic boundaries or known discontinuities in larval supply. These findings suggest that genetic drift is not likely to play a dominant role in affecting color morph frequencies.

Nonetheless, a limited temporal and spatial perspective could mask selective pressures affecting these populations. For example, subtidal populations, which were not sampled, could have different overall color ratios due to selective pressures on color. However, this appears even less likely than in intertidal habitats because $P$. ochraceus would be less affected by environmental conditions such as heat stress while immersed and coloration could only be affected by selective sea otter predation at the small number of our sites supporting otter populations. Alternately, color polymorphisms observed at one time may be under selection toward the dominance of one form (e.g., Stolz et al. 2003). The samples we analyzed do not represent a time series long enough to determine conclusively if the observed color ratios vary over time. However, observations of color ratios of 1,327 P. ochraceus (across all sizes) by biology student Clifford Forbes in 1951 indicated orange frequencies of $20 \%$ in Trinidad, California $\left(41.07^{\circ} \mathrm{N}\right)$, and $25 \%$ at Hopkins Marine Station $\left(36.62^{\circ} \mathrm{N}\right)$ (Forbes 1951), mirroring the values we observed in our samples.

\section{Size-Related Plasticity}

The size-related shift in the frequency of orange color morphs, which has not previously been documented, seems to indicate phenotypic plasticity in this trait. The color shift could arise from diet, ontogenetic differences in mortality, or ontogenetic color change. Adults of both color morphs were consistently observed congregating on the same prey items (e.g., Mytilus californianus). Feder (1959) demonstrated that regardless of geographic location or habitat, $P$. ochraceus overwhelmingly eats the prey it is primarily found with, suggesting that these sea stars feed primarily on the California mussel (M. californianus) throughout its range. Nonetheless, $P$. ocbraceus also will feed opportunistically on many other prey items in our study range 


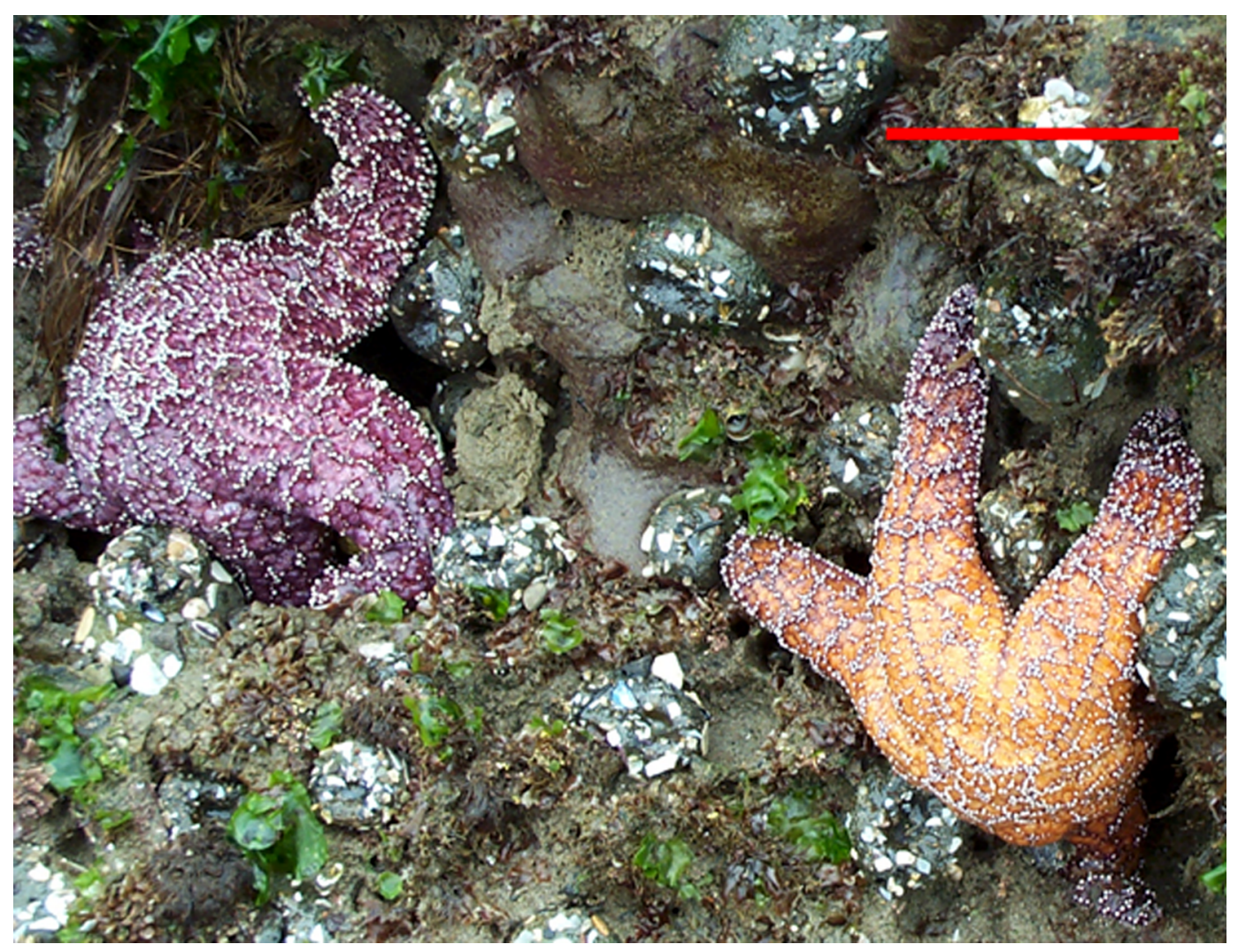

Figure 4. Purple (left) and orange (right) Pisaster ochraceus photographed at low tide at Carpinteria, California, March 2004, by R.D.S. Scale bar approximately $10 \mathrm{~cm}$. Note purple (dark) arm tips on the orange sea star.

(E. Sanford, pers. comm. 2006). Although it is conceivable that mussels of different quality (e.g., reproductive individuals) might affect color or that alternative prey items might impart different color pigments to their predators, it is not clear how (or why) only one sea star color morph would consistently target one type of mussel or alternative food source. However, food sources of juvenile $P$. ochraceus, which are unknown, might ultimately affect adult color patterns. In lobsters, for example, juvenile diet has been shown to affect color patterns through both genetically determined and phenotypically plastic pathways (Tlusty and Hyland 2005).

Hypothetically, P. ochraceus could change color ontogenetically, a phenomenon that oc- curs in other taxa (Booth 1990). Although direct observations of color change have not been made, support for ontogenetic color change in $P$. ocbraceus comes from frequent observations of intermediate-size orange sea stars with purple arm tips (Figure 4), and observations of orange stars regenerating a mostly purple arm bud. Ontogenetic color change in limited parts of an organism's body has been observed in other marine invertebrates (e.g., Tlusty and Hyland 2005). The delayed onset of orange coloration may be related to the cryptic coloration afforded to very small $(<30 \mathrm{~mm})$, nonorange-colored sea stars on coralline algae in our study range, where they are often found as newly settled recruits. This is analogous to Cancer irroratus rock crabs, where coloration is conspicuous in 
adults but cryptic in newly settled juveniles (Palma and Steneck 2001). Moreover, other investigators (E. Sanford, pers. comm. 2006) and we ourselves have noted that most small (e.g., $<30 \mathrm{~mm}$ ) sea stars tend to be grayish purple or grayish brown along the exposed Pacific coast, indicating that adult purple and brown stars also change color but perhaps not as dramatically as orange adults. Apparently, a different pattern is seen in some habitats in the northeastern Pacific where small sea stars are more commonly orange, a color that is more cryptic on their preferred settlement habitat there (R. Paine, pers. comm.), but extensive observations of color ratios at different sizes have not been made for those populations.

\section{Differences with Protected-Water Populations}

The frequencies of color morphs in $P$. ochraceus populations from protected waters in the northeastern Pacific are in stark contrast to those we observed for open-coast populations, which might shed light into the mechanisms underlying color polymorphism in this species. First, protected-water populations are much more variable in color ratios, and individual sites tend to be dominated by one color morph or another. For example, on San Juan Island $\left(48.5^{\circ} \mathrm{N}, 123^{\circ} \mathrm{W}\right)$, purple stars dominate. Of 250 individuals sampled at six sites on San Juan Island by R.D.S. in September 2005 , only $4.8 \%$ were orange. Likewise, purple individuals dominate populations in Georgia Strait (D. Eernisse, pers. obs.) (Harley et al. in press) and at sites along the Inside Passage of southeastern Alaska (C. Baxter, pers. obs.). Yet, on Orcas Island, adjacent to San Juan Island, populations are dominated by orange individuals (R. Strathmann, pers. obs.). In addition, the purple stars in these protected-water populations are far more vivid than their open-coast counterparts, although small numbers of brightly colored purple stars have been observed at open-coast sites (E. Sanford, pers. comm.). At protected sites, orange individuals are much paler in color, and the brown color morph seen on the open coast is largely absent (RDS, pers. obs.).
Wave exposure, water chemistry, and available food resources differ substantially between protected and outer-coast sites. Local differences in wave exposure might become manifest through differences in larval settlement patterns. In the embayments of Puget Sound and other protected waters, founder effects might dominate so that infrequent settlement events skewed by chance toward one color morph or another could result in similarly skewed adult sea star populations. This hypothesis is supported by data on the size structures of $P$. ochraceus populations at six San Juan Island sites, which showed that sea stars $<70-\mathrm{mm}$ radius were absent from 250 sampled individuals compared with $27 \%$ of all observations for the open coast. This finding suggests that recruitment events are more episodic in these protected waters. Salinity and $\mathrm{pH}$ are likely to be different in protected waters compared with open-coast sites, but at present we do not know the effects of water chemistry on sea star pigmentation. Pisaster ochraceus populations in quiet water environments also likely differ from opencoast populations in diet, because Mytilus californianus, a prominent bed-forming space occupier on much of the open Pacific coast, is not found in great densities on San Juan Island or at other protected-water sites. Differences in diet could hypothetically result in different color ratios and different color tones in open- versus protected-water populations, but dietary differences do not explain how polymorphism is maintained with such consistency across the broad geographic range represented by our outer-coast study sites. Moreover, observations from protected-water populations must be taken with caution because it has been suggested (Ricketts et al. 1985) that these populations are a subspecies of $P$. ochraceus (i.e., $P$. ocbraceus confertus).

\section{CONCLUSIONS AND FUTURE DIRECTIONS}

In 1959, Feder lamented, "Although the starfish Pisaster ocbraceus is one of the most conspicuous animals to be found along the rocky shores of the Pacific Coast ... its natural history is poorly known" (Feder 1959:721). Nearly 50 yr later, because of Feder and 
others, knowledge of the natural history of $P$. ocbraceus has increased, but causes of a most obvious characteristic-its striking color polymorphism - remains a mystery.

Several of the key questions raised by our observations can become the focus of a renewed effort to understand patterns of color in P. ochraceus. Elucidation of the gene(s) and pigment complexes responsible for color is a fundamental gap in our understanding of color patterns. Mating experiments involving crosses of variously colored parents might help determine the inheritance patterns of color, although typically high mortality in laboratory cultures may confound interpretation of results. Basic biological questions need to be assessed in an ecological context, considering how variation in diet, water chemistry, and biological interactions can affect pigmentation and the occurrence and mechanisms of color change. Moreover, understanding the extent to which larval dispersal effectively mixes populations will provide insight into the role that genetic drift could play in skewing color ratios. Clarification of population genetic structure and phylogeographic patterns will help to address the question of whether protected-water populations are genetically distinct from one another and from open-water populations. Although addressing these questions will be a challenge, improved understanding of the mechanisms of color variation in this common sea star would be greatly appreciated by the many amateur naturalists and professional biologists who have been intrigued by this conspicuous tide-pool animal.

\section{ACKNOWLEDGMENTS}

We thank D. Eernisse, C. Harley, B. Menge, J. Pearse, E. Sanford, and R. Strathmann for sharing their knowledge of Pisaster ocbraceus. J. Wible of the Miller Library at Hopkins Marine Station provided research assistance. Research in San Juan Island was conducted with the Beam Reach Science and Sustainability Field School. Research by the MultiAgency Rocky Intertidal Network (MARINe) was sponsored by the U.S. Minerals Management Service.

\section{Literature Cited}

Allen, J. A. 1988. Frequency dependent selection by predators. Philos. Trans. R. Soc. Lond. B Biol. Sci. 319:485-503.

Booth, C. L. 1990. Evolutionary significance of ontogenic color change in animals. Biol. J. Linn. Soc. 40:125-163.

Endler, J. 1986. Natural selection in the wild. Princeton University Press, Princeton, New Jersey.

Etter, R. J. 1988. Physiological stress and color polymorphism in the intertidal snail Nucella lapillus. Evolution 42:660680.

Feder, H. M. 1959. The food of the starfish, Pisaster ocbraceus, along the California coast. Ecology 40:721-724.

Finke, O. M. 1994. Female colour polymorphism in damselflies: Failure to reject the null hypothesis. Anim. Behav. 47:12491266.

Forbes, C. 1951. A survey of Pisaster ochraceus colors in separated regions. University of California, Berkeley. Available from Hopkins Marine Station Library, Pacific Grove, California 93950.

Fox, D. L., and T. S. Hopkins. 1966. The comparative biochemistry of pigments. Pages 277-300 in R. A. Boolootian, ed. Physiology of Echinodermata. Interscience, New York.

Fox, D. L., and B. T. Scheer. 1941. Comparative studies of the pigments of some Pacific coast echinoderms. Biol. Bull. (Woods Hole) 80:441-455.

Galeotti, P., D. Rubolini, P. O. Dunn, and M. Fasola. 2003. Colour polymorphism in birds: Causes and functions. J. Evol. Biol. 16:635-646.

George, S. B. 1999. Egg quality, larval growth and phenotypic plasticity in a forcipulate seastar. J. Exp. Mar. Biol. Ecol. 237:203-224.

Gillespie, R. G., and G. S. Oxford. 1998. Selection of the color polymorphism in Hawaiian happy-face spiders: Evidence from genetic structure and temporal fluctuations. Evolution 52:775.

Hairston, N. G. 1979. The adaptive significance of color polymorphism in two spe- 
cies of Diamptomus (Copepoda). Limnol. Oceanogr. 24:15-37.

Harley, C. D. G., M. S. Pankey, J. P. Wares, M. J. Wonham, and R. K. Grosberg. In press. Color polymorphism and genetic structure in the sea star Pisaster ochraceus. Biol. Bull. (Woods Hole).

Horth, L. 2004. Predation and the persistence of melanic male mosquitofish (Gambusia holbrooki). J. Evol. Biol. 17:672-679.

Houde, A. E. 1987. Mate choice based upon naturally occurring colour-pattern variation in a guppy population. Evolution 41:1-10.

Leighton, B. J., J. D. G. Boom, C. Bouland, E. B. Hartwick, and M. J. Smith. 1991. Castration and mortality in Pisaster ochraceus parasitized by Orchitophrya stellarum (Ciliophora). Dis. Aquat. Org. 10:71-73.

Mauzey, K. P., C. Birkeland, and P. K. Dayton. 1968. Feeding behavior of asteroids and escape responses of their prey in the Puget Sound region. Ecology 49:603-619.

Menge, B. A. 1972. Competition for food between two intertidal starfish species and its effect on body size and feeding. Ecology 53:635-644.

Menge, B. A., C. Blanchette, P. Raimondi, T. Freidenburg, S. Gaines, J. Lubchenco, D. Lohse, G. Hudson, M. Foley, and J. Pamplin. 2004. Species interaction strength: Testing model predictions along an upwelling gradient. Ecol. Monogr. 74:663684.

Morris, R. H., D. P. Abbott, and E. C. Haderlie. 1980. Intertidal invertebrates of California. Stanford University Press, Stanford, California.

Nevo, E. 1973. Adaptive color polymorphism in cricket frogs. Evolution 27:353-367.

Oda, K.-I., and M. Ishii. 2001. Body color polymorphism in nymphs and adults of a katydid, Conocephalus maculatus (Orthoptera: Tettigoniidae). Appl. Entomol. Zool. 36:345-348.

Paine, R. T. 1966. Food web complexity and species diversity. Am. Nat. 100:65-75.
Paine, R. T., and A. C. Trimble. 2004. Abrupt community change on a rocky shore-biological mechanisms contributing to the potential formation of an alternative state. Ecol. Lett. 7:441-445.

Palma, A. T., and R. S. Steneck. 2001. Does variable coloration in juvenile marine crabs reduce risk of visual predation? Ecology 82:2961-2967.

Phillips, D. W. 1975. Distance chemoreception-triggered avoidance behavior of limpets (Acmaea). J. Exp. Zool. 191:199-209.

Ricketts, E. F., and J. Calvin. 1939. Between Pacific tides. Stanford University Press, Stanford, California.

Ricketts, E. F., J. Calvin, and J. W. Hedgpeth. 1985. Between Pacific tides. Stanford University Press, Stanford, California.

Sanford, E. 1999. Regulation of keystone predation by small changes in ocean temperature. Science (Washington, D.C.) 283:2095-2097.

Sewell, M. A., and J. C. Watson. 1993. A "source" for asteroid larvae?: Recruitment of Pisaster ochraceus, Pycnopodia belianthoides and Dermasterias imbricata. Mar. Biol. (Berl.) 117:387-398.

Stolz, U., S. Velez, K. Wood, M. Wood, and J. Feder. 2003. Darwinian natural selection for orange bioluminescent color in a Jamaican click beetle. Proc. Natl. Acad. Sci. U.S.A. 100:14955-14959.

Tlusty, M., and C. Hyland. 2005. Astaxanthin deposition in the cuticle of juvenile American lobster (Homarus americanus): Implications for phenotypic and genotypic coloration. Mar. Biol. (Berl.) 147:113-119.

Vasu, B. S., and A. C. Giese. 1966. Protein and non-protein nitrogen in the body fluid of Pisaster ochraceus (Echinodermata) in relation to nutrition and reproduction. Comp. Biochem. Physiol. 19:351-361.

Wente, W. H., and J. B. Phillips. 2003. Fixed green and brown color morphs and novel color-changing morph of the Pacific tree frog Hyla regilla. Am. Nat. 162:461473. 